\title{
NILAI-NILAI RELIGIUS DALAM TEMBANG PAMOJHI RITUAL HODO MASYARAKAT ADAT SUKU PARIOPO
}

\author{
Ainun Najib \& Mukhammad Baharun \\ Universitas Ibrahimy Situbondo, Indonesia \\ Universitas Ibrahimy Situbondo, Indonesia \\ adjie245@gmail.com \& muhammad.baharun@yahoo.co.id
}

\begin{abstract}
:
Hodo is a ceremonial ritual of Pariopo tribe in order to ask for rain. This ritual is survival ancestor since hundred of past which has endured to this day. In spite of development, this ritual changes and developments in line with the changing era and times. Behaviour and diversity society of Pariopo Tribe also influence changes in Hodo's Ritual, because the society of Pariopo Tribe are 100\% Moslems. Acculturation of cultural and religious values seems very united in the implementation of this ritual later. The unification between cultures and religious values can be seen from the poems of Pamojhi songs that were rebounded as long as Ritual takes place. Pamojhi's songs depicted religious values of Islam which is very deep breath. It is the core of the religious teaching from the building joins of faith. The meaning of Pamojhi's songs is one note withIslamic theology. The First is devotion, a belief where there is no God to worship except Allah. And the Second is petition and Connection, its mean of certainty about power of the one supreme which regulates al human life. So, the third is surrender, human of submission form slave to ruler after pass up petition or attempt to get something which be desired. These values are embodied in the magic spell ritual worship in the implementation of Hodo, either explicitly or implicitly, that the ritual could be accepted by society and survive until now.
\end{abstract}

Keywords: Nilai-nilai Religius, Tembang Pamojhi, Ritual Hodo, Masyarakat Adat, Suku Pariopo

\section{A. Pendahuluan}

Indonesia memiliki banyak ragam suku bangsa dengan perbedaan-perbedaan kebudayaan, yang tercermin pada pola hidup dan perilaku masing-masing. Keragaman budaya atau cultural diversity adalah sebuah keniscayaan yang selalu ada dalam kehidupan masyarakat di belahan dunia, salah satunya adalah Indonesia. Dalam konteks pemahaman masyarakat majemuk, selain kebudayaan suku-suku bangsa, masyarakat Indonesia juga terdiri dari berbagai kebudayaan daerah yang

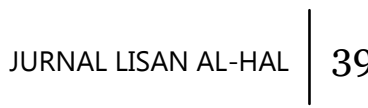


bersifat kewilayahan, yang merupakan pertemuan atau akulturasi dari berbagai kebudayaan kelompok suku-suku bangsa lain yang ada di daerah tersebut.

Salah satu masyarakat adat yang ada di Indonesia adalah suku Pariopo. Pariopo adalah nama sebuah dusun yang terletak di desa Bantal Kecamatan Asembagus Kabupaten Situbondo. Dusun ini berada di dataran tinggi dan berbukit. Penduduk dusun Pariopo sebagian besar adalah suku Madura yang beragama Islam, hal ini dibuktikan dengan dijadikannya bahasa Madura yang merupaan bahasa komunikasi seha-hari. Aktivitas sebagian besar masyarakat dusun Pariopo adalah berpetani dan beternak. Namun aktifitas pertanian mereka tidak selamanya berjalan dengan baik, mengingat lahan pertanian yang ada memiliki jenis tanah yang kering, serta dusun Pariopo termasuk wilayah yang memiliki curah hujan rendah. Tak heran bila masyarakat setempat sangat tergantung pada curah hujan dalam aktivitas hidup lingkungannya.

Masyarakat dusun Pariopo juga masih mempertahankan seni dan tradisi peninggalan nenek moyang yaitu tarian ritual Hodo. Ritual Hodo adalah bentuk upacara masyarakat suku Pariopo untuk meminta hujan jika terjadi kemarau yang berkepanjangan, yang dalam masyarakat setempat dikenal dengan istilah nimur kara. Menurut O'Dea, ritual merupakan bentuk perayaan atau upacara (celebration), yang memiliki berhubungan dengan kepercayaan atau agama tertentu, yang ditandai dengan sifat-sifat khusus, serta melahirkan rasa hormat yang luhur sebagai suatu pengalaman yang suci. ${ }^{1}$ Dalam pelaksanaannya, ritual Hodo terdiri dari berbagai macam kesenian yang ada di dalamnya, diantaranya adalah musik, tarian dan tembang. Berdasarkan fungsinya, Soedarsono mengklasifikasikan kesenian menjadi tiga, yaitu sebagai sarana ritual, sebagai ungkapan rasa pribadi seseorang, dan sebagai pertunjukan yang bernilai estetik. $^{2}$ Melalui klasifikasi tersebut, maka Hodo termasuk kesenian sebagai sarana ritual.

Penyebaran suku-suku yang ada di Indonesia juga berpengaruh pada kebudayaan masyarakat sesuai dengan kondisi alam di sekitarnya. Mereka mendiami wilayah dengan kondisi geografis yang berbeda-beda. Mulai dari gunung, pinggiran hutan, pesisir pantai dataran rendah, pedesaan hingga perkotaan. Pun demikian halnya dengan perkembangan peradaban manusia dan penyebaran agama-agama di Indonesia turut

\footnotetext{
${ }^{1}$ Sumandiyo Hadi, Seni dalam Ritual Agama (Yogyakarta: Pustaka, 2006), 31.

2 R.M. Soedarsono, Seni Pertunjukan Indonesia di Era Globalisasi (Yogyakarta: Gadjah Mada University Press, 2010), 123.

40 JURNAL LISAN AL-HAL
} 
menjadi faktor pendukung yang mengokohkan eksistensi kebudayaan masyarakat dengan keragaman corak yang berbeda. Lahirnya kebudayaan-kebudayan khas yang bernuansakan agama ini, membuktikan kebudayaan tersebut bisa terus bertahan dan diterima dari generasi ke generasi.

Ritual Hodo mengalami perkembangan dari waktu ke waktu sesuai perubahan zaman. Perkembangan tersebut merupaan pnyempurnaan dari berbagai sisi dengan tetap mempertahankan pakempakem yang sudah menjadi esensi ritual Hodo. Penyempurnaan disesuaikan dengan perubahan zaman yang semakin modern, sehingga kesenian ritual Hodo terus berkesinambungan, diterima dan diteruskan generasi selanjutnya. Selain hal tersebut, Pengaruh ajaran agama Islam terhadap budaya ritual hodo lambat laun menyusup dan menyesuaikan diri dengan tanpa mengurangi eksistensi masing-masing. Islam sebaga agama tidak meniggalkan syari'at dan ajaran-ajarannya, dan ritual hodo tetap dilaksanakan dan terus bertahan hingga hari ini. Sehingga yang terjadi adalah harmoni penyatuan antara budaya lokal masyarakat dengan nilai-nilai religius yang tertanam di dalamnya. Penelitian ini difokuskan pada penggalian secara konseptual tentang nilai-nilai religius yang terdapat dalam tembang pamojhi (pemujaan) ritual Hodo masyarakat adat suku Pariopo, sebagai ritual meminta hujan dan kesuburan tanah.

\section{B. Sejarah Ritual Hodo}

Ritual Hodo adalah salah satu warisan kebudayaan yang masih tetap dipertahankan oleh masyarakat adat suku Pariopo hingga hari ini. Lahirnya ritual Hodo memiliki akar sejarah yang akan terus melekat dalam kehidupan masyarakat Pariopo. Menurut Ke Absu, Ketua Adat Suku Paripo, ritual Hodo merupakan warisan kebudayaan nenek moyang yang telah melintasi lima generasi, hingga saat ini seni Hodo tetap dilestarikan dan akan terus diwariskan kepada generasi-generasi di masa yang akan datang. ${ }^{3}$ Kata Hodo merupakan bahasa Madura dari kata dasar Do Hodo, yang memiliki makna di atas langit ada langit. Kata tersebut kemudian lebih akrab didengar dan diucapkan dengan Hodo. Ritual Hodo dapat dikatakan sebagai suatu pagelaran seni yang terdiri dari seni musik, seni tari dan seni suara yang saling terpadu dan menjadi bentuk pertunjukan yang utuh.

Belum diketahui secara pasti sejak kapan awal kemunculan seni ritual Hodo ini. Namun menurut legenda yang hidup di masyarakat

\footnotetext{
${ }^{3}$ Ke Absu, Wawancara Pribadi, 8 Nopember 2016, Desa Bantal Asembagus.
}

$$
\begin{array}{l|l}
\text { JURNAL LISAN AL-HAL } & 41
\end{array}
$$


setempah, bahwa pada masa kerajaan Majapahit daerah tersebut merupakan perlintasan pejabat kerajaan, yaitu Raden Damarwulan, suami Kencono Wungu, Ratu kerajaan Majapahit. Raden Damarwulan sendiri merupakan keponakan Patih Logender, seorang abdi kerajaan Majapahit yang terkenal sakti. Raden Damarwulan diutus untuk menaklukkan Kadipaten Blambangan dan membunuh Adipati Blambangan Menak Jinggo, yang memberontak dan menolak untuk membayar upeti kepada pusat kekuasaan yaitu Kerajaan Majapahit. Beberapa fakta sejarah penulisankan, bahwa Kadipaten Blambangan memang pernah ditaklukkan oleh Majapahit (1295-1527).

Setelah berhasil menaklukkan Kadipaten Blambangan dan membunuh Menak Jinggo, rombongan Raden Damarwulan kembali ke Majapahit, dengan jalur perjalanan menyusuri pantai utara Pulau Jawa. Rombongan Raden Damarwulan sempat singgah dab neristirahat di suatu tempat yang panas, kering dan bertanah tandus. Lokasi tersebut terletak diantara dua bukit yang kemudian disebut dengan "Dukuh Pariopo". Raden Damarwulan bersama rombongannya merasa haus dan lapar, maka Raden Damarwulan memerintahkan anak buahnya untuk membuat tungku batu sebagai tempat memasak, yang kemudian disebut Batu Tomang (tungku). Setelah pembuatan tungku selesai, muncul masalah selanjutnya yaitu kesulitan air untuk memasak. Maka Raden Damarwulan melakukan semedi di salah satu goa tak jauh dari Batu Tomang, dengan maksud meminta petunjuk kepada Sang Penguasa Alam. Malam hari itu Raden Damarwulan memperoleh petunjuk yaitu; menyembelih hewan ternak kambing berwarna hitam di kaki gunung Masali, Menyiapkan sesaji di sekitar Batu Tomang sebagai sarana permohonan kepada Tuhan agar segera diberikan hujan. Melalui pelaksanaan petunjuk-petunjuk tersebut, akhirnya permohonan tersebut dikabulkan oleh Sang Maha Kuasa melalui rahmat-Nya berupa turunnya hujan, maka rombongan Raden Damarwulan beserta penduduk Pariopo selamat dari kehausan dan bencana kekeringan. ${ }^{4}$

Namun menurut penelitian mutakhir yang dipaparkan oleh Irwan Rakhday, legenda Raden Damarwulan tersebut belum bisa dibuktikan secara ilmiah. Mengingat Raden Damarwulan adalah tokoh fiksi dalam pewayangan rakyat Jawa yang kisahnya diangkat dari Serat Damarwulan, yang diperkirakan di tulis pada akhir kekuasaan Majapahit. Sehingga tidak mungkin tokoh fiksi ada dalam sejarah lahirnya ritual Hodo. ${ }^{5}$ Dalam

${ }^{4}$ Ibid.

${ }^{5}$ Irwan Rakhday, Wawancara Pribadi, 5 Desember 2016, Asembagus.

$42 \mid$ JURNAL LISAN AL-HAL 
pewayangan, Damarwulan digambarkan sebagai sosok protagonis yang rupawan, arif dan bijaksana, disukai banyak wanita serta mengayomi rakyatnya. Sosok ini dipertentangkan dengan tokoh antagonis Menak Jinggo yang pemberontak karena Ratu Kencana Wungu tidak memenuhi janji untuk menjadikannya suami, meskipun Menak Jinggo telah berhasil menaklukkan pengacau Kebo Marcuet yang mengamuk di kerajaan Majapahit. Lebih lanjut Irwan menyampaikan bahwa penuturan Ke Absu itulah yang lebih dapat diterima. Ke Absu adalah merupakan generasi keempat dari pembabat alas Pariopo pertama kali yaitu Jhu' Modhi. Sehingga diduga $J h u^{\prime}$ Modhi ini pula lah yang menggagas tradisi Hodo. ${ }^{6}$

Dikisahkan bahwa Jhu' Modhi dan Jhu' Hayap adalah dua orang buronan pemerintah kolonial Belanda. Keduanya merupakan penduduk dusun Tol-tol Kecamatan Arjasa yang melarikan diri dari pencarian Belanda. Mereka berdua lalu mendami hutan belantara di Pariopo dan membuka lahan pertanian hingga berkeluarga dan beranak-cucu. Sumber lain ada pula yang menyebutkan nama Jhu' Sembang dan Jhu' Eni. Namun Ke Absu menekankan bahwa keturunan dari Jhu' Modhi yang paling banyak menghuni wilayah tersebut. Bahkan makam Jhu' Modhi dan Jhu' Hayap ada di dusun tersebut. ${ }^{7}$

Pada awalnya, para pamojhi-pamojhi melakukan ritual hodo dalam kelompok-kelompok kecil yang tersebar di beberapa tempat di dusun Pariopo, seperti Bato Tomang, Goa Macan, Tapak Dangdang, Cangkreng, Asta Tekos dan lain-lain. Namun pada tahun 2004, budayawan Chandra Noratio memberikan masukan agar ritual ini dilaksanakan menjadi satu kelompok yang bersifat massal. Tanpa mengurangi kesakralan ritual tersebut, dimasukkanlah kalimat-kalimat thoyyibah yang bernafaskan Islam. Hal ini sangat relevan dengan kondisi masyarakat Pariopo yng kini seratus persen beragama Islam. ${ }^{8}$

Berdasarkan konteks historisnya terdapat proses akulturasi dalam ritual Hodo. Parameter pengertian akulturasi disini, pertama merujuk pada suatu bentuk perubahan budaya akibat pertemuannya dengan budaya lain; kedua, proses perubahan budaya yang dibedakan dari proses inovasi, difusi, invensi maupun penemuan; dan ketiga, sebagai konsep kata sifat yang digunakan untuk menunjuk pada suatu kondisi tertentu, seperti misalnya kondisi budaya kelompok yang satu lebih

${ }^{6}$ Irwan Rakhday, "Suku Pariopo: Identifikasi yang Mengokohkan," Jawa Pos, Radar Banyuwangi, 19 September 2015.

${ }^{7}$ Ibid.

${ }^{8}$ Ibid. 
terakulturasi dari budaya yang lain. ${ }^{9}$ Persinggungan antarbudaya Majapahit, Islam dan Madura menciptakan kebaruan pada ritual Hodo.

Masuknya agama Islam di tanah Jawa, secara perlahan turut mempengaruhi terhadap budaya-budaya dan kesenian tradisional yang masih bertahan di masyarakat, salah satunya adalah Ritual Hodo pelaksanaan ritual Hodo tidak dilarang seketika, melainkan orientasinya yang diubah lebih kepada mempertahankan budaya dan kesenian, dengan disisipi ajaran-ajaran keislaman. Maka Hodo bertransformasi menjadi kesenian yang syarat dengan nilai-nilai ajaran Islam, meski terdapat unsur keaslian yang dipelihara, namun hal itu tidak bertentangan secara prinsip dengan syariat Islam, sehingga seni Hodo tetap tetap lestari serta dapat diterima oleh masyarakat, bahkan masyarakat luar desa Bantal banyak hadir untuk mengikuti upacara kesenian Hodo tersebut. ${ }^{10}$ Selain ajaran Islam, Hodo juga tidak terlepas dari budaya Madura. Hal ini terlihat dari teks mantra/tembang pamojhi yang menggunakan bahasa Madura, mengingat bahasa Madura adalah bahasa komunikasi penduduk Pariopo sehari-hari.

Masyarakat dusun Pariopo tetap mempertahankan tradisi Hodo sebagai peninggalanleluhur mereka karena sangat dirasakan manfaatnya, yaitu menurunkan hujan untuk kesuburan tanah ladang-ladang pertanian mereka. Pelaku Hodo yang tergabung dalam suatu tim tetap melaksanakan format prosesi seperti sedia kala, meskipun muatan di dalamnya sudah banyak mengalami perubahan. Mulai dari timpat pelaksanaan Hodo, tahapan-tahapan hingga pelaksanaan tetap diyakini sama dengan yang dipraktikkan oleh Raden Damarwulan. ${ }^{11}$

Menurut Ke Tohasan, ritual hodo dilaksanakan untuk kepentingan orang banyak. Yaitu untuk kemaslahan seluruh warga Situbondo yang dilanda kemarau berkepanjangan. Jadi tidak hanya untuk warga Pariopo saja. Bahkan Ke Tohasan mempersilahkan kepada segenap warga yang berkenan hadir untuk mengikuti pagelaran dan gelar doa bersama dalam pelaksanaan ritual Hodo. Baginya, ritual Hodo adalah permohonan yang meminta hujan kepada Sang Maha Pencipta, jadi tidak bertentangan dengan ajaran agama. ${ }^{12}$

\footnotetext{
${ }^{9}$ Sumandiyo Hadi, Seni dalam Ritual Agama, 35.

${ }^{10}$ Irwan Rakhday, "Sekelumit Kisah dari Bumi Pariopo (Upacara Adat Hodo)," Nopember 2016

11 Panakajaya Hidayatullah, "Upacara Seni Hodo sebagai Ritual Kesuburan Masyarakat Dukuh Pariopo Situbondo" (Yogyakarta: Pengkajian Seni Pertunjukan dan Seni Rupa, Universitas Gadjah Mada, 2015), 15.

${ }^{12}$ Ke Tohasan, Wawancara Pribadi, Nopember 2016, Desa Bantal Asembagus. Baca

$44 \mid$ JURNAL LISAN AL-HAL
} 


\section{Pelaksanaan Upacara Ritual Hodo}

Ritual Hodo terdiri dari beberapa tahapan prosesi yang harus dilalui. Sebelum dilaksanakan acara inti dari ritual hodo, masyarakat terlebih dahulu melakukan prosesi yang begitu rumit dan sakral (praritual). Pra-ritual merupakan rangkaian dari ritual Hodo yang harus dilaksanakan, karena dipercaya oleh masyarakat setempat sebagai syarat yang harus dilakukan untuk suatu pengharapan atas kelancaran pelaksanaan pada acara inti. Pra-ritual umumnya memang sering dilaksanakan oleh sebagian seni tradisi di Indonesia sebagai permohonan kepada Tuhan untuk memberikan kelancaran dan keberkahan dalam proses upacara atau ritual yang akan dilaksanakan.

\section{Tahap Pesucen}

Hal pertama yang harus dilakukan oleh para pelaku Hodo adalah tahap penyucian diri atau pesucen. Tahapan ini harus dilakukan oleh seluruh pelaksana Hodo yang terdiri dari pemagku ritual (adat), musisi, pengrawit serta penari. Penyucian diri ini dilakukan di suatu sumber mata air yang oleh masyarakat setempat disebut dengan se capcap. Kata se capcap merupakan bahasa Madura yang memiliki makna "yang menetes", disebut se capcap karena letak mata air ini berada di dinding curah yang airnya terus mengalir. Latak mata air se capcap tersebut berada di lembah perbukitan yang jauh dari pemukiman warga. Akses jalan menuju mata air se capcap cukup sulit dan melelahkan, menyusuri jalan tanah perbukitan yang cukup curam dan terjal, sehingga memerlukan ketangguhan fisik untuk mencapainya.

Pelaksanaan tahap pesucen biasanya dilakukan pada sore hari menjelang petang. Satu demi satu para pelaku upacara membersihkan diri dengan mandi dan bersesuci dengan berwudhu. Pesucen dipimpin langsung oleh pemangku ritual dengan menyiramkan air kepada seluruh pelaksana ritual, dengan maksud mensucikan diri secara lahir dan batin untuk menghadap Sang Pencipta. Melalui hati dan pikiran yang bersih, diharapkan permohonan melalui do'a-do'a yang dipanjatkan dapat dikabulkan. ${ }^{13}$ Secara lahiriyah, tahapan pesucen dianggap sebagai salah satu tahapan ritual untuk memohon turunnya hujan, namun dibalik itu terdapat makna mendalam, bahwa pesucen tersebut dianggap sebagai

juga: “Warga Pariopo Gelar Ritual Hodo,” Jawa Pos, Radar Banyuwangi, 4 Nopember 2015.

${ }^{13}$ Chandra Noratio, "Sinopsis Ritual Budaya Hodo: Tarian Sakral Minta Hujan" (Dokumen Kecamatan Asembagus, 2006), . 8.

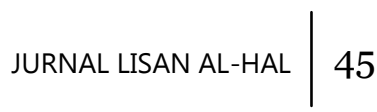


wujud kecintaan manusia terhadap alam sekitarnya. Pengkeramatkan masyarakat terhadap sumber mata air se capcap pada dasarnya merupakan wujud kepedulian mereka untuk menjaga dan melestarikan keseimbangan alam.

\section{Tahapan Semedi}

Setelah tahap pesucen selesai, maka selanjutnya adalah tehap semedi. Para pelaku ritual mendatangi suatu goa untuk melaksanakan semedi di malam hari. Masyarakat setempat menamakan goa tersebut dengan goa Macan, yang konon juga menjadi tempat persemedian Raden Damarwulan saat memohon petunjuk meminta diturunkannya hujan. Selama melakukan semedi semalam suntuk, para pelaku ritual tidak boleh tidur, melainkan memanjatkan do'a-do'a hingga pagi menjelang. ${ }^{14}$ Do'ado'a yang dipanjatkan sesuai dengan apa yang diajarkan dalam agama Islam, memohon kepada Allah agar mendapatkan rahmat dari-Nya berupa diturunkannya hujan. Selain itu, permohonan serta do'a agar pelaksanaan ritual esok harinya berjalan dengan baik dan lancar, serta mendapat keberkahan turunnya hujan.

\section{Tahapan Berkurban}

Setelah tahap semedi selesai, tahap selanjutnya adalah tahapan berkurban (penyembelihan hewan kurban) sebagai ungkapan rasa syukur kepada Allah SWT. Tahap berkurban ini juga didasarkan kepada kisah Raden Damarwulan yang memperoleh petunjuk dari Tuhan untuk melakukan penyembeihan hewan ternak berupa kambing berwarna hitam. Lokasi penyembelihan hewar kurban ini dilakukan di suatu bukit yang bernama gunung Masali. Daging hewan kurban tersebut dimasak untuk dijadikan sajian saat upacara ritual berlangsung bersama nasi tumpeng, dan akan dimakan bersama-sama setelah upacara selesai. ${ }^{15}$ Berkurban dalam rangkaian upacara Hodo bermakna sebagai simbol kesuburan tanah atau kesejahteraan bagi masyarakat dusun Pariopo. Selanjutnya para pelaku ritual mempersiapkan perlengkapanperlengkapan lain upacara ritual Hodo. Perlengkapan lainnya yaitu alat musik tradisional berupa gamelan, gendang, dan seruling. Selain itu para pelaku ritual dilengkapi dengan kostum (pakaian adat untuk ritual) berupa celana hitam, odheng (ikat kepala) berwarna merah dan hitam, selendang, serta ikat pinggang dan gelang aksesoris yang terbuat dari

${ }^{14}$ Ibid.
${ }^{15}$ Ibid.

46 JURNAL LISAN AL-HAL 
janur kelapa.

\section{Pelaksanaan Ritual Hodo}

Setelah persiapan upacara sudah lengkap, maka selanjutnta seluruh pelaksana ritual menuju Batu Tomang, sebagai tempat pelaksanaan ritual Hodo. Tomang dalam bahasa Madura bermakna tungku, disebut Batu Tomang karena di lokasi tersebut berdiri tiga batu besar yang menyerupai tungku untuk memasak. Rongga tengah-tengah diantara tiga batu besar tersebutlah yang menjadi lokasi pelaksanaan ritual Hodo. Para pelaku ritual duduk bersila membentuk formasi melingkar mengelilingi sesaji. Seorang pemangku ritual berdiri dan mengitari lingkaran tersebut dengan menebarkan asap pembakaran kemenyan atau dupa. Selanjutnya seseorang pelaku ritual lainnya melantunkan kidung (intro), dengan harapan agar pelaksanaan ritual tersebut dapat berjalan dengan lancar dan penuh khidmat. Kidung yang dilantunkan tersebut disebut dengan "Tembang Pamojhi", yang dilantunkan oleh satu orang, namun sesekali diikuti oleh para pelaku ritual lainnya.

Selama pembacaan tembang pamojhi tersebut, para pelaku ritual lainnya "mengamini" dengan sikap mengangkat tangan dan mengayunkannya ke atas dan ke bawah secara berulang-ulang. Gerakan tersebut bermakna suatu permohonan kepada Tuhan Sang Pemilik Semesta. Selanjutnya alat musik mulai dimainkan oleh masing-masing musisi secara berurutan, sementara pelaku ritual lainnya mulai beranjak berdiri hingga semua alat musik dimainkan. Dengan iringan musik lengkap dan tembang pamojhi, selanjutnya para pelaku ritual mulai menari sesaji denan tetap membentuk formasi melingkar. Pada ujung pelaksanaan ritual, satu demi satu para pengunjung yang menyaksikan di pinggir arena upacara diajak untuk turut serta menari bersama. Kemudiann ritual Hodo diakhiri dengan berdoa serta makan bersama. Di akhir pelaksanaan ritual biasanya ditandai dengan turunnya hujan di lokasi tersebut seketika itu juga.

\section{Syair-Syair Tembang Pamojhi}

Sebelum memulai acara, para pelaku ritual Hodo melakukan tawassul kepada para nabi, tabi'in, tabiut tabi'in, syuhada', awliya', shalihin serta para leluhur-leluhur mereka. Dalam agama Islam wasilah diyakini sebagai cara seorang hamba untuk mendekatkan diri kepada Allah melalui perantara orang-orang yang menjadi kekasih-Nya. Setelah wasilah dilakukan, maka acara ritual hodo pun siap untuk dimulai dengan diawali 
pembacaan syair tembang pamojhi.

Syair tembang pamojhi yang terdapat pada ritual hodo berasal dari puisi dengan berbahasa Madura. Tembang pamojhi Hodo dibagi menjadi dua bagian, yaitu pada bagian pertama adalah syair dari kidung tua yang dinyanyikan oleh pengrawit. Pada saat awal mula upacara ritual (intro) dimulai. Makna dari syair kidung tua ini lebih cenderung bermakna suatu penghambaan dan doa kepada Allah. Bagian kedua adalah bagian syair untuk lagu pengiring tarian Hodo, yang dinyanyikan setelah kidung tua dinyanyikan, bagian kedua ini adalah syair yang dinyanyikan bersamaan dengan tarian Hodo. Bait syair pada tarian Hodo ini terdapat pengulangan sebanyak dua kali baik bagian yang pertama maupun bagian yang kedua. Pada pengulangan yang kedua kalinya bait-bait syair tersebut diselingi dengan lantunan dua kalimat syahadat. ${ }^{16}$ Berikut ini adalah bagian pertama Syair Hodo yaitu kidung pembuka, beserta arti dalam bahasa Indonesia, yang dinyanyikan di awal atau introduction.

A'udu Billahi Minassyaithanirrojim

(Aku berlindung kepada Allah dari godaan Syetan yang terkutuk)

Bissmillahirrohmanirrahim

(Dengan menyebut nama Allah yang Maha Pengasih lagi Maha Penyayang)

Tembang pamojhi kaule

(inilah tembang puji-pujian kami)

Pamojhina socce kalaben ate se pote

(Pujian yang suci dengan hati yang putih bersih)

Kaangguy ngadep Ajunan Guste

(untuk menghadap Engkau wahai Tuhan kami)

Moga-moga pangistoa parnyoonan nak poto Adam

(semoga terkabul permohonan anak cucu Adam)

Son nak Poto Abididen Nabi Adam

(Untuk semua anak cucu Nabi Adam)

Wekasane Nabi Muhammad

(Meneruskan (ajaran) Nabi Muhammad)

Sengko'jeneng alif, Alif iku Popocogi

(Akulah yang bernama alif, alif itu adalah ciptaan)

Sang pangocap Sapa Liwepa

(Sang Maha Berkehendak bagi apa saja yang Dia Kehendaki)

Sengko' Makhlukka Allah

(Aku adalah makhluk Allah)

\footnotetext{
${ }^{16}$ Ke Tohasan, Wawancara Pribadi.
}

48 JURNAL LISAN AL-HAL 
Mandhi, mandhi, mandhi Diye

(terkabullah, terkabullah, terkabullah disini)

Sendit Jibril cangking Malaikat

(melalui Jibril sang pegangan para Malaikat)

Ondhem dateng, Ondhem deteng, Ondhem dateng

(wahai awan datanglah, wahai awan datanglah, wahai awan datanglah)

Mon Geggere, Mon geggere

(Duh turunlah, Duh turunlah)

Berikut ini adalah syair bagian kedua tembang pamojhi ritual Hodo yang menadi pengiring tarian hodo, beserta arti dalam bahasa Indonesia :

Tarian Hodo

Dangdangkep Sere Kekep

(Daun Sirih yang bertepi-tepi)

Mon Majid Mara ngocap

(Jika orang mati mari berbicara)

Mon Manossa Mara Nyanggikep

(Jika Manusia jangan berbicara)

Somor Bandung Talage Petteng

(Sumur bendungan telaga hitam)

Sabuhoni Moge Ondem

(Berharap Semoga Awan Mendung Datang)

Petteng dateng, Petteng dateng

(Mendung hitam datanglah, Mendung hitam datanglah)

Malaikat Papat Tekka

(Malaikat mohon datangkan hujan)

Tekka Dateng, Tekka Dateng

(Kabulkan dan datangkanlah, kabulkan dan datngkanlah)

Saksena Para Wali

(disaksikan oleh Para Wali)

Wawaline Nabi Muhammad

(Para Wali (penerus) Nabi Muhammad)

Pada teks syair mantra berbahasa Madura di atas tampak sebagai suatu Puji-pujian yang merupakan suatu bentuk permohonan hamba kepada Allah Yang Maha Kuasa. Tembhang pamojhi merupakan permohonan kepada Tuhan dengan menggunakan unsur-unsur Islami. Mantra tersebut memberikan gambaran tentang sekumpulan orang yang mewakili penduduk desa untuk meminta hujan kepada Allah. 


\section{E. Nilai-Nilai Religius Dalam Tembang Pamojhi}

Secara keseluruhan, tahapan-tahapan prosesi yang dilakukan, tampak jelas pelaksanaan ritual Hodo sarat dengan muatan nilai-nilai keIslaman. Tahap pesucen, semedi dan menyembelih hewan kurban sebagaimana disebutkan di atas senada dengan anjuran dalam agama Islam yang bermakna hubungan antara hamba dengan Tuhannya serta hubungan antar sesama manusia. Secara fisik bersesuci dalam Islam ialah merupakan kegian mensucikan diri dari hadas maupun najis, sehingga seseorang diperbolehkan untuk mengerjakan suatu ibadah (menghadap Allah). Begitu pula dengn semedi, yang merujuk pada praktik-praktik tasawuf praktis para kaum sufi melalui media dzikir dan tafakkur. Sedangkan anjuran meyembelih hewan ternak yang memang disyariatkan dalam Al-Qur'an dan as-Sunnah serta diperkuat oleh Ijma ulama' sebagai wujud syukur atas nikmat-nikmay-Nya. Berkurban juga memiliki dimensi makna agar manusia bisa saling berbagi kepada sesama.

Selain itu, setiap syair tembang pamojhi dalam ritual Hodo, baik bagian pertama maupun kedua juga memiliki makna spiritual-religius yang terkandung di dalamnya. Pargament mengartikan Spiritualitas sebagai sebuah pencarian terhadap sesuatu yang suci (a search for the sacred). ${ }^{17}$ Lebih lanjut Levine, yoo, Aviv, Ewing dan Au menambahkan bahwa spiritualitas sebagai sebuah hubungan antara seorang individu dengan sesuatu yang tidak tampak secara fisik dan mental, memiliki beberapa elemen seperti makna, tujuan, dan hubungan dengan sesuatu yang memiliki kekuatan yang jauh melebihi apa yang dimiliki individu tersebut. ${ }^{18}$ Dengan kata lain bahwa spiritualitas merupakan makna yang tidak dapat dipisahkan dengan religiusitas, meskipun ruang lingkup spiritualitas lebih luas. Dari bait-bait yang dilantunkan dalam ritual Hodo dapat kita ambil beberapa hikmah, diantaranya adalah:

\section{Penghambaan}

Nilai pertama yang dapat diambil dari syair ritual pojhian Hodo adalah wujud penghambaan/keabdian. Hal ini dapat dilihat dari bait syair

17 Taufik Achmad Dwi Putro, "Islamic Work Ethic: Studi Kasus Nilai-Nilai Spiritualitas Islam Pada PT. Andromeda" (Tesis, Fakultas Psikologi Universitas Gadjah Mada Yogyakarta, 2015), 3.

${ }^{18}$ Ibid.

50 JURNAL LISAN AL-HAL 
pembuka ritual hodo. Sebagaimana hakikat penciptaan manusia dan jin adalah untuk megabdi kepada Allah. Penghambaan adalah merupakan wujud kecintaan dan kesadaran manusia dan makhluk-makhluk Allah lainnya untuk tunduk dan patuh kepada-Nya dengan menjalankan segala perintah dan menjauhi segala larangan-Nya. Dimensi penghambaan manusia mencakup aspek lahir dana batin, keduanya tidak bisa dilakukan secara parsial pada waktu ataupun tempat tertentu saja.

Penghambaan kepada sang pencipta harus senantiasa menyeimbangkan potensi rohaniah dan potensi jasmaniah, untuk dijadikan sebagai bekal dalam melakukan pengabdian kepada Allah secara tulus dan ikhlas. Untuk mengabdi kepada Allah secara baik, manusia harus memiliki iman yang benar, yaitu meyakini bahwa Allah lah sebahagai satusatunya dzat yang layak dan seharusnya disembah serta tempat mengabdikan diri secara utuh. Inti penghambaan manusia adalah tauhid, yaitu mengesakan Allah dengan seluruh sifat-sifatnya dan tidak membuat sekutu dengan makhluk-Nya. Dengan demikian dapat dipahami bahwa tauhid dapat menyadarkan manusia, dirinya dan segala yang dimiliki adalah seluruhnya milik Allah. Dengan sepenuh hati manusia menerima Allah sebagai penguasa tunggal dalam kehidupan, sebagai sumber haqiqi kebenaran yang memiliki kehendak dan kekuasaan bagi seluruh alam.

\section{Permohonan dan Wasilah}

Secara lahiriah, bait-bait syair yang terucap dalam tembang pamojhi ritual Hodo merupakan bentuk dimana subjek melakukan munajat dengan hati yang bersih, tulus dan ikhlas. Subjek berkeyakinan bahwa terdapat kekuatan besar yang mampu mengabulkan segala permohonan dan keinginan yang diminta, yaitu berupa rahmat diturunkannya hujan dan kesuburan tanaman. Kekuatan transenden yang dituju adalah kekuasaan Allah. Seseorang yang ikhlas dalam melakukan perbuatan, tujuan dan cita-cita amalnya hanya semata-mata karena Allah, maka manusia itu akan disertai oleh Allah dalam berbagai situasi dan keadaan dimana saja mereka berada.

Dalam tembang pamojhi ritual Hodo, munajat yang dipanjatkan juga disertai dengan wasilah melalui kekasih-kekasih Allah. Ada dua nama nabi dan malaikat Allah yang disebutkan dalam syair-syair pamojhi tersebut, yaitu Nabi Muhammad, Nabi Adam, Malaikat Jibril, Malaikat pembawa hujan (Izrofil) dan para wali penerus Nabi Muhammad. Nabi Adam dimaknai sebagai representasi bapak seluruh umat manusia yang ada di muka bumi ini. Sementara Nabi Muhammad adalah merupakan Rasul mulia penyempurna agama Islam yang risalah-risalahnya diterima 
dari Allah melalui malaikat Jibril. Bagi kalangan Islam Ahlussunnah wal Jama'ah, wasilah diyakini sebagai jembatan yang akan mempermudah segala permohonan agar tersampaikan kepada Allah dan dikabulkan olehNya. Keistimewaan-keistimewaan kekasih Allah yang dapat memudahkan dan terkabulkannya doa tersubut disebut dengan syafaat. Syafaat kekasihkekasih Allah ini tetap arus diminta kepada Sang Pemberi Syafaat yaitu Allah SWT.

\section{Berserah Diri}

Manusia tidak pernah tahu apa yang Allah rencanakan untuk kehidupannya. Dengan ketidaktahuan inilah seharusnya manusia tetap memiliki prasangka baik kepada Allah atas peristiwa-peristiwa yang telah Allah pilihkan untuk hamba-Nya. Inilah wujud kepasrahan kepada Sang Khaliq. Kepasrahan disini bukan berarti menerima nasib tanpa adanya perjuangan. Namun kepasrahan adalah wujud penyerahan diri dari Segala aktifitas kehidupan manusia yang selalu disandarkan kepada Allah sebagai Tuhannya, setelah dilakukannya berbagai usaha dan doa. Nilai kepasrahan juga tersirat di dalam tembang pamojhi ritual Hodo masayarakat adat suku Pariopo. Dari pelaksanaan ritual permohonan diturunkannya hujan, mereka menyadari bahwa Allah dzat yang Maha Esa lah yang akan mengabulkan segala permohonan, terhadap sapa saja yang Allah kehendaki. Mereka sebagai manusia anak cucu Adam hanya bisa memohon dan berdoa.

Hakikat dari kepasrahan diri manusia adalah kesadaran akan keterbatasan kekuatan dan kemampuan dalam melakukan segala pekerjaan. Tanpa adanya pertolongan dari Allah yang Maha Berkehendak, tentu manusia bukanlah apa-apa. Totalitas kepasrahan dengan menganggap bahwa tidak ada kekuatan melainkan kekuatan Allah akan membawa dampak positif pada setiap tindakan yang dilakukan oleh manusia. Kepasrahan diri akan memberikan ketenangan secara batin dan menganggap bahwa apa yang diterimanya adalah pilihan terbaik dari Allah serta menganggap segala peristiwa pasti mengandung nilai kebaikan. Dengan kepasrahan kepada Allah inilah manusia akan menjlani kehidupan di jalan yang benar, tanpa keraguan, kegelisahan dan kehawatiran yang berlebihan. Kepasrahan manusia akan membawa kesadaran bahwa sebaik-baik rencana manusia, jauh lebih baik rencana yang Allah siapkan untuknya.

\section{F. Simpulan}

Ritual Hodo adalah merupakan upacara adat masyarakat suku

$$
52 \mid \text { JURNAL LISAN AL-HAL }
$$


Pariopo yang berlansung secara turun-temurun dari generasi ke generasi yang tetap bertahan hingga hari ini. Ritual ini merupakan upacra adat dalam rangka memohon agar diturunkannya berkah Tuhan, yaitu berupa hujan. Dalam perjaanannya ritual Hodo ini mengalami akulturasi antara budaya lokal masyarakat dengan nilai-nilai agama yang berkembang, yaitu agama Islam. Sehingga tak heran jika mantra atau tembang pamojhi dalam ritual Hodo ini sarat denan nilai-nilai religius yang bernuansa Islami.

Sedikitnya terdapat tiga makna dasar nilai-nilai religius yang tersirat dalam tembang pamojhi ritual Hodo tersebut. Antara lain adalah nilai penghambaan, permohonan dan wasilah serta berserah diri kepada Allah. Dimana ketiga nilai ini pada dasarnya merupakan inti dari ajaran agama Islam dari bangunan sendi-sendi keimanan, yang dalam konsep keimanan dalam Islam dikenal dengan istilah tauhid. Tauhid adalah merupakan konsep aqidah dalam Islam yang menyatakan dan meyakini keesaan Allah. Seorang muslim harus yakin bahwa tauhid adalah pondasi keberislaman yang paling agung serta hakikat Islam yang paling mendasar, sebagai salah satu syarat akan diterimanya amal perbuatan manusia.

Aqidah Asy'ariyah membagi pengamalan tauhid ke dalam tiga bagian, yaitu tauhid rububiyah, tauhid uluhiyah dan asma wa sifat. Tauhid rubiyah adalah keberimanan manusia terhadap keesaan Allah sebagai satu-satunya Tuhan yang memiliki, merencanakan, menciptakan, mengatur, memelihara, memberi rezeki, memberikan manfaat menolak mudharat serta menjaga seluruh alam semesta. Sedangkan tauhid uluhiyah adalah wujud keberimanan manusia bahwa hanya Allah yang patut disembah dan tidak ada sekutu bagi-Nya. Beriman terhadap uluhiyah Allah merupakan konsekwensi dari keimanan terhadap rububiyah-Nya, yaitu mengesakan Allah dalam setiap ibadah yang dilakukan. Sedangkan tauhid Asma wa Sifat adalah keberimanan terhadap sifat dan nama-nama Allah yang baik (asmaul husna), yang sesuai dengan keagungan-Nya.

Seluruh esensi ketiga konsep tauhid tersebut telah tergambar dalam tembang pamojhi ritual masyarakat adat suku Pariopo dalam melaksanakan ritual Hodo serta tidak bertentangan dengan ajaran-ajaran tauhid. Meskipun ritual Hodo ini sama sekali berbeda dengan ritual shalat istisqa' yang diajarkan oleh salafunas shalih yang juga memiliki tujuan permohonan turunnya hujan. Hal ini semakin menegaskan bahwa dalam ritual hodo telah terjadi akulturasi antara budaya masyarakat suku Pariopo dengan nila-nilai agama Islam, sehingga ritual hodo yang menjadi kekayaan budaya masyarakat adat suku Pariopo ini patut untuk dilestarikan dan diperkenalkan kepada publik. 
"Tembang Pamojhi Ritual Hodo"

54 JURNAL LISAN AL-HAL 


\section{DAFTAR PUSTAKA}

Noratio, Chandra. "Sinopsis Ritual Budaya Hodo: Tarian Sakral Minta Hujan." Dokumen Kecamatan Asembagus, 2006.

Hidayatullah, Panakajaya. Upacara Seni Hodo sebagai Ritual Kesuburan Masyarakat Dukuh Pariopo Situbondo. Yogyakarta: Pengkajian Seni Pertunjukan dan Seni Rupa, Universitas Gadjah Mada, 2015.

R.M. Soedarsono. Seni Pertunjukan Indonesia di Era Globalisasi. Yogyakarta: Gadjah Mada University Press, 2010.

Sumandiyo Hadi. Seni dalam Ritual Agama. Yogyakarta: Pustaka, 2006.

Achmad, Taufik, Dwi Putro. "Islamic Work Ethic: Studi Kasus Nilai-Nilai Spiritualitas Islam Pada PT. Andromeda." Tesis, Fakultas Psikologi Universitas Gadjah Mada Yogyakarta, 2015.

Irwan Rakhday. "Sekelumit Kisah dari Bumi Pariopo (Upacara Adat Hodo)," Nopember 2016.

_-_. "Suku Pariopo: Identifikasi yang Mengokohkan." Jawa Pos, Radar Banyuwangi, 19 September 2015.

"Warga Pariopo Gelar Ritual Hodo." Jawa Pos, Radar Banyuwangi, 4 Nopember 2015

Irwan Rakhday, Wawancara Pribadi, 5 Desember 2016. Asembagus.

Ke Absu. Wawancara Pribadi, 8 Nopember 2016. Desa Bantal Asembagus.

Ke Tohasan. Wawancara Pribadi, 8 Nopember 2016. Desa Bantal Asembagus. 